\title{
Introducing Fuzziness in CDS Pricing under a Structural Model
}

\author{
Liang Wu $\mathbb{D}^{1,2}$ Jian-guo Sun $\mathbb{D}^{1},{ }^{1}$ and Xian-bin $\mathrm{Mei}^{2}$ \\ ${ }^{1}$ Postdoctoral Research Station, Henan University, Kaifeng 475000, Henan, China \\ ${ }^{2}$ Postdoctoral Research Base, Henan Institute of Science and Technology, Xinxiang 453003, Henan, China \\ Correspondence should be addressed to Liang Wu; nidewuliang@163.com
}

Received 12 August 2017; Revised 19 April 2018; Accepted 2 May 2018; Published 31 May 2018

Academic Editor: Elisa Francomano

Copyright (C) 2018 Liang Wu et al. This is an open access article distributed under the Creative Commons Attribution License, which permits unrestricted use, distribution, and reproduction in any medium, provided the original work is properly cited.

\begin{abstract}
OTC credit derivatives are nonstandardized financial derivatives which have the following characteristics. (1) Information on trades is not public. (2) There is no performance guarantee from the stock exchange. (3) The bigger the risk in performance, the bigger the price floating. These result in an asymmetry of market information flow and this asymmetry acts as a decisive factor in the credit risk pricing of financial instruments. The asymmetry of market information flows will lead to obvious fuzziness in how counterparty risks are characterized, as in the process of valuing assets when discontinuous jumping takes place. Accurately measuring the amplitude and frequency of asset values when influenced by information asymmetry cannot be arrived at just by analyzing the random values of historical data. With this in mind, this paper hypothesizes both asset value jump amplitude and frequency of random parameters as a triangular fuzzy interval, i.e., a new double exponential jump diffusion model with fuzzy analysis. It then gives a credit default swap pricing formula in the form of fuzziness. Through the introduction of fuzzy information, this model has the advantage of being able to arrive at results in the form of triangular fuzziness and, consequently, being able to solve some inherent problems in a world characterized by asymmetry in the flow of market information and, to a certain extent, the inadequate disclosure of information.
\end{abstract}

\section{Introduction}

Information disclosure bridges the asymmetry of information between issuers and investors as disclosure can reduce information asymmetry. However, OTC credit derivatives, as nonstandardized financial derivatives, have the following characteristics; trading information is neither open to the public nor is there a guarantee from a stock exchange on the performance of a credit derivative. Furthermore, bigger the risk in how a credit derivative performs, bigger the price floating. As a result, asymmetry in the flow of market information acts as a decisive factor in the sensitivity of pricing of financial instrument credit risks and this will thus lead to obvious fuzziness in the estimation of counterparty risks. For example, when some emergencies are related to financial institutions and followed by movements in stocks and stock markets, the dissemination of adverse information will lead to counterparty default behavior. At the same time, internal market credit defaults will be both convergent and infectious. Thus, it should be remembered that a counterparty default is characterized not only by synchronicity and aggregation but also by fuzziness and uncertainty. In the pricing of credit default swap counterparty risks, the effects of both external market shocks and the internal effect of contagion on a company cannot be observed, i.e., the precise value cannot be gotten through a set of random values. As a consequence, the study of fuzziness, hesitation, presentation, and how things tend to evolve under conditions of asymmetric information is extremely important in controlling the outbreak, diffusion, and aggregation of credit risks. In addition, the combining of fuzziness and randomness under conditions of asymmetric information can lead to more efficient tools that are used to strip, transfer, and hedge credit risk pricing and so build a much closer model of the real credit derivatives market. The credit risk analysis in fuzzy and uncertain environments and the derivatives pricing model in this paper are of great realistic and theoretical significance.

Article [1] introduced, for the first time, the concept of fuzzy information into credit risk analysis and the modeling of derivatives pricing. Default strength was assumed to be a fuzzy triangle reflecting the relationship between corporate defaults and actual market information under the shadow of a 
current financial crisis. Article [2] discussed the issue of credit default swap pricing by adding fuzziness and hesitation to a circular default intensity model in uncertain environments where the output variables had both randomness and fuzziness at the same time. Papers $[3,4]$ studied credit derivative LCDS and TRS pricing in the fuzzy random environment. Paper [5] summarized the application of fuzzy information in the pricing of credit derivatives in recent years, introduced the theory of uncertainty into the pricing of CDS, and put forward a One-Factor Fuzzy Copula function which builds a foundation for the pricing of portfolio credit products. However, almost all the above literature focuses on pricing determined by the reduced-form models; few of them have ever studied credit risk analysis and its derivatives pricing. The structural default model combines a company's default event with its ability to repay debt and, by intuitively defining a default time, can better explain actual default events; this has become the classic model of credit derivatives pricing. Therefore, it is necessary to analyze credit default risks and construct a credit default swap pricing model in a fuzzy random environment from the perspective of a pricing structural model.

Inspired by [6, 7], this paper combined fuzziness and randomness to look at the credit default swap pricing problem in fuzzy random environments by using a pricing structural model. The derivatives market environment has the following characteristics. Information concerning the environment in which trading takes place is not open to the public, the stock exchange offers no guarantee of performance and bigger the risk in how a derivative may perform, bigger the price floating. This paper assumes that credit default swaps of reference credit asset values are driven by the double exponential jump diffusion model. For the fuzziness in the markets caused by market information flow asymmetry, this paper assumes that the asset value range of movement is a triangular fuzzy number. At the same time, in order to take the influence of interest rate risks on swap pricing into consideration, this paper assumes that the market short-term interest rates can satisfy the CIR model and make it fuzzy. The fuzzy credit default swap pricing model can be achieved by using the structural model to calculate the probability of asset default. The advantage of this model is to be able to show the results in a triangular fuzziness form through the introduction of fuzzy information. This solves some inherent problems as to the flow of information in an asymmetric market and, to a certain extent, the inadequate disclosure of information.

\section{Credit Default Swap Pricing Model}

A credit default swap is an agreement between two trading parties through which the CDS buyer will transfer an asset credit risk to a credit guarantee seller. In return, the CDS buyer pays some fees to the credit guarantee seller who takes the risk for the duration of the contract. The seller promises to compensate the CDS buyer for the specific loss if there is a default within the contract time. The corresponding reference entity refers to a third party asset excepting CDS buyers and sellers, or risks they transfer are the third party entity credit risk. The reference entity can be a single specific economic entity or a portfolio. CDS premiums paid by the buyer are determined by CDS market prices. The stream of premiums is called the premium leg, and the compensation when a credit event occurs is called the protection leg.

In credit default swaps, we assume $A$ is the credit guarantee buyer, $B$ is the credit guarantee seller, and the credit spread $c$ is what $A$ pays $B$ and, finally, what $B$ pays $A$ is the reference asset in the case of breach of contract. In structuring the credit derivative pricing model, if we assume the reference credit asset is $V_{0}$, its face value $N$ at time $t_{0}$ is the par value, the payment of interest is in discrete points, $0<t_{1}<t_{2}<\cdots<$ $t_{N}=T$ and the reference entity and the credit default swaps have the same due date, then the cash $A$ pays in the future is

$$
\begin{aligned}
P V(\text { premium leg })= & c N \sum_{i=1}^{n} \exp \left(-\int_{0}^{t_{i}} r_{s} d s\right) \\
& \times 1_{\left\{\tau>t_{i}\right\}} \Delta t_{i}+A_{p}, \\
\text { among which } A_{p}= & \frac{1}{2} c N \sum_{i=1}^{n} \exp \left(-\int_{0}^{t_{i}} r_{s} d s\right) \\
& \times\left[F\left(t_{i}\right)-F\left(t_{i-1}\right)\right] \Delta t_{i},
\end{aligned}
$$

For simplification we assume that default can occur at the payment date or in the middle of two consecutive payment dates. Therefore, the average accrual payment $A_{p}$ can also be estimated (see [8]) by $A_{p}=(1 / 2) c N \sum_{i=1}^{n} \exp \left(-\int_{0}^{t_{i}} r_{s} d s\right) \times$ $\left[F\left(t_{i}\right)-F\left(t_{i-1}\right)\right] \Delta t_{i}$.

$1_{\left\{\tau>t_{i}\right\}}$ is the default indicator function, i.e., when the reference asset defaults the function value is 1 ; otherwise, it is $0 . \tau$ is the reference asset default time. The cash $B$ pays in the future is

$$
\begin{aligned}
P V & (\text { protection leg }) \\
& =(1-\delta) N \sum_{i=1}^{n} \exp \left(-\int_{0}^{t_{i}} r_{s} d s\right)\left[F\left(t_{i}\right)-F\left(t_{i-1}\right)\right] .
\end{aligned}
$$

According to the principle of no arbitrage pricing, the expected cash $A$ and $B$ pay should be equal under risk neutral measures.

$$
E^{\mathrm{Q}}[P V(\text { protection leg })]=E^{\mathrm{Q}}[P V(\text { premium leg })],
$$

that is,

$$
\begin{gathered}
E^{Q}\left[c N \sum_{i=1}^{n} \exp \left(-\int_{0}^{t_{i}} r_{s} d s\right) \times 1_{\left\{\tau>t_{i}\right\}} \Delta t_{i}+A_{p}\right] \\
=E^{Q}\left[(1-\delta) N \sum_{i=1}^{n} \exp \left(-\int_{0}^{t_{i}} r_{s} d s\right)\right. \\
\left.\cdot\left[F\left(t_{i}\right)-F\left(t_{i-1}\right)\right]\right]
\end{gathered}
$$

Thus, the formula to calculate the credit default swap fair premium (or swap prices) can be obtained by 


$$
c=\frac{E^{\mathrm{Q}}\left[(1-\delta) \sum_{i=1}^{n} \exp \left(-\int_{0}^{t_{i}} r_{s} d s\right)\left[F\left(t_{i}\right)-F\left(t_{i-1}\right)\right]\right]}{E^{\mathrm{Q}}\left[\sum_{i=1}^{n} \exp \left(-\int_{0}^{t_{i}} r_{s} d s\right) \times 1_{\left\{\tau>t_{i}\right\}} \Delta t_{i}+(1 / 2) \sum_{i=1}^{n} \exp \left(-\int_{0}^{t_{i}} r_{s} d s\right) \times\left[F\left(t_{i}\right)-F\left(t_{i-1}\right)\right] \Delta t_{i}\right]}
$$

where $E^{\mathrm{Q}}$ is the expected value under the risk neutral measure and $\exp \left(-\int_{0}^{t_{i}} r_{s} d s\right)$ is the account process or discount factor. Obviously, the key to solving function (5) is calculating the reference asset default probability.

\section{The Fuzzy Analysis for CDS Pricing}

3.1. The Default Distribution with Fuzzy Analysis. To calculate the reference entities default distribution, this paper adopts a first-hitting time structural model. Put forward in the work by [9], this model regards default as an endogenous variable that is related to a company's assets value. Then it uses asset value and liability information to construct the default distribution model.

This study assumes that the reference asset value $V(t)$ follows a geometric Lévy process, i.e., $V_{t}=V_{0} e^{X_{t}}, V_{0}>$ $0, X_{t}=\mu t+\sigma W_{t}+\sum_{i=1}^{N(t)} Y_{i}$, in which $N(t)$ is the Poisson process with intensity $\lambda>0, W_{t}$, a standard Brownian movement, $\left\{Y_{i}\right\}$, a list of independent identically distributed nonnegative random variables that are used to depict asset value jump sizes whose density function is the asymmetric double exponential distribution $f(y)=p \eta_{1} e^{-\eta_{1} y} 1_{\{y \geq 0\}}+$ $q \eta_{2} e^{\eta_{2} y} 1_{\{y<0\}}, \eta_{1}>1, \eta_{2}>0$. In this function, $p$ stands for the probability of an up-jump in value, $q$ for the probability of a down-jump in value, and $p+q=1,1 / \eta_{1}, 1 / \eta_{2}$, the average value of the jump. In addition, all random processes $N(t), W_{t}$, and $\left\{Y_{i}\right\}$ are mutually independent; i.e., asset value $V(t)$ obeys the double exponential jump diffusion process. A double exponential distribution has a unique advantage in describing asset jumps, one being that it allows both for up and down jumps. Moreover, jump sizes can also be asymmetrical allowing a description of both the peak and the tail of financial data corresponding to asymmetric disclosures of market information; the other is that it has infinite memory, making the calculation of expectation and variance much easier.

Under the crisp number condition, suppose $\theta \in\left(-\eta_{2}, \eta_{1}\right)$, then the moment generating function of jump variable $\left\{Y_{i}\right\}$ is $E^{Q}\left[e^{\theta Y_{t}}\right]=e^{G(\theta) t}$, in which $G(\theta)=\mu \theta+(1 / 2) \sigma^{2} \theta+\lambda\left(p \eta_{1} /\left(\eta_{1}-\right.\right.$ $\left.\theta)+q \eta_{2} /\left(\eta_{2}+\theta\right)-1\right)$ is the Laplace index of the Lévy process. The lemma of the solution of the Laplace index equation $G(\theta)$ can be used for the default time of Laplace transformation.

Lemma 1 ([10]). For any $\alpha>0$, equation $G(\theta)=\alpha$ has only four real roots: $\beta_{1, \alpha}, \beta_{2, \alpha},-\beta_{3, \alpha},-\beta_{4, \alpha}$, and $-\infty<-\beta_{4, \alpha}<$ $-\eta_{2}<-\beta_{3, \alpha}, 0<\beta_{1, \alpha}<\eta_{1}<\beta_{2, \alpha}<\infty$.

To introduce fuzzy analysis into a description of the default distribution, let us review some basic knowledge of fuzzy mathematics.
Definition 2 ([11]). Suppose $\mathrm{R}$ is a set of real numbers, and the fuzzy set $\widetilde{A}$ refers to ordered real pair $\widetilde{A}=\{(x, \mu(x)): x \in X\}$, in which $\mu(x)$ is a membership function of fuzzy set $\widetilde{A}$ that map $x \in X$ to the closed zone $[0,1]$.

Proposition 3 ([12]). Let $\tilde{a}$ and $\widetilde{b}$ be two fuzzy numbers, $\tilde{a}_{\gamma}=$ $\left[\widetilde{a}_{\gamma}^{-}, \widetilde{a}_{\gamma}^{+}\right], \widetilde{b}_{\gamma}=\left[\widetilde{b}_{\gamma}^{-}, \widetilde{b}_{\gamma}^{+}\right]$; then $\widetilde{a}+\widetilde{b}, \widetilde{a}-\widetilde{b}, \widetilde{a} \times \widetilde{b}$ are also fuzzy numbers; their level set $\gamma-$ is

$$
\begin{aligned}
&(\widetilde{a}+\widetilde{b})_{\gamma}=\left[\widetilde{a}_{\gamma}^{-}+\widetilde{b}_{\gamma}^{-}, \widetilde{a}_{\gamma}^{+}+\widetilde{b}_{\gamma}^{+}\right] ; \\
&(\widetilde{a}-\widetilde{b})_{\gamma}=\left[\widetilde{a}_{\gamma}^{-}-\widetilde{b}_{\gamma}^{+}, \widetilde{a}_{\gamma}^{+}-\widetilde{b}_{\gamma}^{-}\right] ; \\
&(\widetilde{a} \times \widetilde{b})_{\gamma}=\left[\min \left\{\widetilde{a}_{\gamma} \widetilde{b}_{\gamma}^{-}, \widetilde{a}_{\gamma}^{-} \widetilde{b}_{\gamma}^{+}, \widetilde{a}_{\gamma}^{+} \widetilde{b}_{\gamma}^{-}, \widetilde{a}_{\gamma}^{+} \widetilde{b}_{\gamma}^{+}\right\},\right. \\
& \max \left\{\left\{\widetilde{a}_{\gamma}^{-} \widetilde{b}_{\gamma}^{-}, \widetilde{a}_{\gamma}^{-} \widetilde{b}_{\gamma}^{+}, \widetilde{a}_{\gamma}^{+} \widetilde{b}_{\gamma}^{-}, \widetilde{a}_{\gamma}^{+} \widetilde{b}_{\gamma}^{+}\right\}\right],
\end{aligned}
$$

If the level set $\widetilde{b}_{\gamma}$ to $\forall \gamma \in[0,1]$ does not include zero, then $\tilde{a} / \widetilde{b}$ is also fuzzy number, and its $\gamma-$ is

$$
\begin{aligned}
& \left(\frac{\widetilde{a}}{\widetilde{b}}\right)_{\gamma}=\left[\min \left\{\frac{\widetilde{a}_{\gamma}^{-}}{\widetilde{b}_{\gamma}^{-}}, \frac{\widetilde{a}_{\gamma}}{\widetilde{b}_{\gamma}^{+}}, \frac{\widetilde{a}_{\gamma}^{+}}{\widetilde{b}_{\gamma}^{-}}, \frac{\widetilde{a}_{\gamma}^{+}}{\widetilde{b}_{\gamma}^{+}}\right\},\right. \\
& \left.\max \left\{\frac{\widetilde{a_{\gamma}}}{\widetilde{b}_{\gamma}^{-}}, \frac{\widetilde{a_{\gamma}}}{\widetilde{b}_{\gamma}^{+}}, \frac{\widetilde{a}_{\gamma}^{+}}{\widetilde{b}_{\gamma}^{-}}, \frac{\widetilde{a}_{\gamma}^{+}}{\widetilde{b}_{\gamma}^{+}}\right\}\right] .
\end{aligned}
$$

In addition, let $\lambda>0$ be a real number; then $(\lambda \widetilde{a})_{\gamma}:=$ $\left[\lambda \widetilde{a_{\gamma}}, \lambda \widetilde{a}_{\gamma}^{+}\right], \gamma \in[0,1]$.

As mentioned above, when market information flow is asymmetric, the factors influencing financial product pricing are not only random, but also ambiguous. To show how fuzziness influences derivatives pricing in the process of the asset value jumps, let us assume that the intensity of the asset value jump $\tilde{\lambda}$ and the amplitudes $\widetilde{\eta}_{1}, \widetilde{\eta}_{2}$ are triangular fuzzy numbers:

$$
\begin{aligned}
& \tilde{\lambda}_{\gamma}=\left[\lambda-(1-\gamma) a_{0}, \lambda+(1-\gamma) b_{0}\right], \\
& \tilde{\eta}_{1, \gamma}= {\left[\eta_{1}-(1-\gamma) a_{1}, \eta_{1}+(1-\gamma) b_{1}\right], } \\
& \tilde{\eta}_{2, \gamma}=\left[\eta_{2}-(1-\gamma) a_{2}, \eta_{2}+(1-\gamma) b_{2}\right], \\
& \\
& \gamma \in[0,1](\gamma \text { for reliability }) .
\end{aligned}
$$


Thus, if $\beta_{1, \alpha}, \beta_{2, \alpha}$ are two and only two real roots of $G(\theta)=\alpha$, the level set $\gamma$ - of equation $G(\theta)=\alpha$ can be obtained from $[10,11]$ in a fuzzy random environment:

$$
\begin{aligned}
& \tilde{\beta}_{1, \alpha, \gamma}=\left[\beta_{1, \alpha}-(1-\gamma) a_{3}, \beta_{1, \alpha}+(1-\gamma) b_{3}\right], \\
& \tilde{\beta}_{2, \alpha, \gamma}=\left[\beta_{2, \alpha}-(1-\gamma) a_{4}, \beta_{2, \alpha}+(1-\gamma) b_{4}\right]
\end{aligned}
$$

$$
\gamma \in[0,1]
$$

When the reference asset value is lower than the default gate value $K$, the reference entity will default, and the default time is defined as $\tau=\inf \left\{t \geq 0, V_{t} \leq K\right\}=\inf \left\{t \geq 0, X_{t} \leq\right.$ $\left.K^{*}\right\}, K^{*}=\log K / V_{0}<0$, so the distribution function of the default time of reference entity is

$$
F(t)=F(\tau \leq t)=F\left(\inf _{0 \leq s \leq t} X_{s} \leq K^{*}\right) .
$$

In a fuzzy random environment, the default time $\tau$ has the following Laplace transformative formula:

$$
\begin{aligned}
E^{Q}\left(e^{-\alpha \tau}\right)= & \frac{\widetilde{\eta}_{1}-\widetilde{\beta}_{1, \alpha}}{\tilde{\eta}_{1}} \frac{\widetilde{\beta}_{2, \alpha}}{\widetilde{\beta}_{2, \alpha}-\widetilde{\beta}_{1, \alpha}} e^{-K^{*} \widetilde{\beta}_{1, \alpha}} \\
& +\frac{\widetilde{\beta}_{2, \alpha}-\widetilde{\eta}_{1}}{\widetilde{\eta}_{1}} \frac{\widetilde{\beta}_{1, \alpha}}{\widetilde{\beta}_{2, \alpha}-\widetilde{\beta}_{1, \alpha}} e^{-K^{*} \widetilde{\beta}_{2, \alpha}},
\end{aligned}
$$

so the distribution function of the default time is

$$
\begin{aligned}
\widehat{F}(\alpha) & =\int_{0}^{\infty} e^{-\alpha t} F(\tau \leq t) d t=\frac{1}{\alpha} \int_{0}^{\infty} e^{-\alpha t} d F(\tau \leq t) \\
& =\frac{1}{\alpha} E^{Q}\left(e^{-\alpha \tau}\right) .
\end{aligned}
$$

Then from Gaver-Stehfest's Laplace inversion algorithm, the analytical expressions of default can be made:

$$
F(t)=F(\tau \leq t)=\lim _{n \rightarrow \infty} \widehat{F}_{n}(t),
$$

in which $\widehat{F}_{n}(t)=(\log 2 / t)((2 n) ! / n !(n-$ 1)!) $\sum_{k=0}^{n}(-1)^{k}\left(\begin{array}{l}n \\ k\end{array}\right) \widehat{F}((n+k)(\log 2 / t))$.

To accelerate the convergence, items $n=1,2$ in $\widehat{F}_{n}(t)$ can be neglected, i.e.,

$$
F(t) \approx \sum_{k=1}^{n}(-1)^{n-k} \frac{k^{n}}{k !(n-k) !} \widehat{F}_{k+2}(t)
$$

and when $n$ is big enough, $\sum_{k=1}^{n}(-1)^{n-k}\left(k^{n} / k !(n-k) !\right) \widehat{F}_{k+2}(t)-$ $F(t)=o\left(n^{-k}\right), n \rightarrow \infty$. Eventually, the level set $\gamma-$ of the reference asset value distribution in a fuzzy random environment can be obtained in the form of a triangular fuzzy number:

$$
\begin{aligned}
\widetilde{F}_{\gamma}(t)=\left[F(t)-(1-\gamma) a_{5}, F(t)+(1-\gamma) b_{5}\right] & \\
\gamma & \in[0,1] .
\end{aligned}
$$

3.2. The Credit Default Swap Pricing Model with Fuzzy Analysis. For a description of interest rate risk, $r(t)$, this paper uses the CIR model, i.e., $d r_{t}=\alpha^{\prime}\left(k^{\prime}-r_{t}\right) d t+\sigma^{\prime} \sqrt{r_{t}} d W_{t}$, in which $\alpha^{\prime}$ stands for the recovery rate of interest, $k^{\prime}$ for long-term average, $\sigma^{\prime}$ for volatility, and $W_{t}$ for standard Brownian motion. The price of no default zero coupon bonds is $p(t, T)=E^{\mathrm{Q}}[D(t)]=E^{\mathrm{Q}}\left[\exp \left(-\int_{t}^{T} r_{s} d s\right)\right]$. According to Theorem 4.3.1 in [13],

$$
\begin{aligned}
& \begin{array}{l}
p(t, T)=e^{-r_{t} C(t, T)-A(t, T)} \\
C(t, T) \\
\quad=\frac{e^{\rho(T-t)}-e^{-\rho(T-t)}}{\left(\rho+(1 / 2) \alpha^{\prime}\right) e^{\rho(T-t)}+\left(\rho-(1 / 2) \alpha^{\prime}\right) e^{-\rho(T-t)}} \\
A(t, T)=-\alpha^{\prime} k^{\prime} \int_{t}^{T} C(s, T) d s,
\end{array}
\end{aligned}
$$

The financial data may not be timely or accurate due to unforeseen circumstances or man-made errors, resulting in interest rates in different banks or financial institutions not being the same. Although the differences may be minute, it is not reasonable to assume that they are fixed. In order to reflect the influence of fuzziness on interest rates, this paper also assumes that market short-term interest rates are triangular fuzzy numbers,

$$
\begin{aligned}
\tilde{r}(t)=\left[r(t)-(1-\gamma) a_{6}, r(t)+(1-\gamma) b_{6}\right], & \\
& \gamma \in[0,1] .
\end{aligned}
$$

Theorem 4. Suppose that the market short-term interest rate $\tilde{r}(t)$ satisfies the CIR model, then, the $\gamma$-cut of the price of default-free zero coupon bonds, whose face value is $\$ 1$ and whose expiration date is $T$, can be written as $\widetilde{p}_{\gamma}(t, T)=$ $\left[\tilde{p}_{\gamma}^{-}, \tilde{p}_{\gamma}^{+}\right]$, where the left and right ends can be written, respectively, as

$$
\begin{aligned}
& \tilde{p}_{\gamma}^{-}(t, T)=e^{-\left(1+(1-\gamma) c^{+}\right) r C(t, T)-A(t, T)}, \\
& \tilde{p}_{\gamma}^{+}(t, T)=e^{-\left(1-(1-\gamma) c^{-}\right) r C(t, T)-A(t, T)},
\end{aligned}
$$

$$
\gamma \in[0,1]
$$

Proof. Based on the monotonicity of the function and Proposition 3, we come to this conclusion.

From the first-hitting time structural model, it can be known that the default time and interest rate process are independent from each other, so the triangular fuzziness credit default swap pricing formula comes as follows.

Theorem 5. The left point of level set $\gamma$ - of the fair premium of credit default swaps in the form of triangular fuzziness is 


$$
\begin{aligned}
& \widetilde{c}_{\gamma}^{-} \\
& =\frac{(1-\delta) \sum_{i=1}^{n} e^{-\left(1+(1-\gamma) c^{+}\right) r C(t, T)-A(t, T)}\left[\left(1-(1-\gamma) d^{-}\right) F\left(t_{i}\right)-\left(1+(1-\gamma) d^{+}\right) F\left(t_{i-1}\right)\right]}{\sum_{i=1}^{n} e^{-\left(1-(1-\gamma) c^{-}\right) r C(t, T)-A(t, T)}\left\{\left[1-\left(1-(1-\gamma) d^{-}\right) F\left(t_{i}\right)\right]+(1 / 2)\left[\left(1+(1-\gamma) d^{+}\right) F\left(t_{i}\right)-\left(1-(1-\gamma) d^{-}\right) F\left(t_{i-1}\right)\right]\right\} \Delta t_{i}}
\end{aligned}
$$

Proof. In a fuzzy random environment, according to formulas (5), (15), and (18) and the nature of expectations, the following can be gotten:

$$
\begin{aligned}
& \widetilde{c_{\gamma}^{-}}=\frac{E^{\mathrm{Q}}\left[(1-\delta) \sum_{i=1}^{n} \exp \left(-\int_{0}^{t_{i}} r_{s} d s\right)\left[F\left(t_{i}\right)-F\left(t_{i-1}\right)\right]\right]_{\gamma}^{-}}{E^{\mathrm{Q}}\left[\sum_{i=1}^{n} \exp \left(-\int_{0}^{t_{i}} r_{s} d s\right) \times 1_{\left\{\tau>t_{i}\right\}} \Delta t_{i}+(1 / 2) \sum_{i=1}^{n} \exp \left(-\int_{0}^{t_{i}} r_{s} d s\right) \times\left[F\left(t_{i}\right)-F\left(t_{i-1}\right)\right] \Delta t_{i}\right]_{\gamma}^{+},} \\
& E^{\mathrm{Q}}\left[(1-\delta) \sum_{i=1}^{n} \exp \left(-\int_{0}^{t_{i}} r_{s} d s\right)\left[F\left(t_{i}\right)-F\left(t_{i-1}\right)\right]\right]_{\gamma}^{-} \\
& \quad==(1-\delta) \sum_{i=1}^{n} e^{-\left(1+(1-\gamma) c^{+}\right) r C(t, T)-A(t, T)}\left[\left(1-(1-\gamma) d^{-}\right) F\left(t_{i}\right)-\left(1+(1-\gamma) d^{+}\right) F\left(t_{i-1}\right)\right], \\
& \begin{aligned}
E^{\mathrm{Q}}\left[\sum_{i=1}^{n} \exp \left(-\int_{0}^{t_{i}} r_{s} d s\right) \times 1_{\left\{\tau>t_{i}\right\}} \Delta t_{i}\right]_{\gamma}^{+}=\sum_{i=1}^{n} e^{-\left(1-(1-\gamma) c^{-}\right) r C(t, T)-A(t, T)}\left[1-\left(1-(1-\gamma) d^{-}\right) F\left(t_{i}\right)\right], \\
E^{\mathrm{Q}}\left[\frac{1}{2} \sum_{i=1}^{n} \exp \left(-\int_{0}^{t_{i}} r_{s} d s\right) \times\left[F\left(t_{i}\right)-F\left(t_{i-1}\right)\right] \Delta t_{i}\right]_{\gamma}^{+} \\
\quad=\frac{1}{2} \sum_{i=1}^{n} e^{-\left(1-(1-\gamma) c^{-}\right) r C(t, T)-A(t, T)}\left[\left(1+(1-\gamma) d^{+}\right) F\left(t_{i}\right)-\left(1-(1-\gamma) d^{-}\right) F\left(t_{i-1}\right)\right] \Delta t_{i} .
\end{aligned}
\end{aligned}
$$

Bring the expected results into formula (5), and according to the monotonicity of function, this theorem can be proved.
Theorem 6. The right point of level set $\gamma-$ of the fair premium of credit default swaps in the form of triangular fuzziness is

$$
\begin{aligned}
& \widetilde{c}_{\gamma}^{+} \\
& =\frac{(1-\delta) \sum_{i=1}^{n} e^{-\left(1-(1-\gamma) c^{-}\right) r C(t, T)-A(t, T)}\left[\left(1+(1-\gamma) d^{+}\right) F\left(t_{i}\right)-\left(1-(1-\gamma) d^{-}\right) F\left(t_{i-1}\right)\right]}{\sum_{i=1}^{n} e^{-\left(1+(1-\gamma) c^{+}\right) r C(t, T)-A(t, T)}\left\{\left[1-\left(1+(1-\gamma) d^{+}\right) F\left(t_{i}\right)\right]+(1 / 2)\left[\left(1-(1-\gamma) d^{-}\right) F\left(t_{i}\right)-\left(1+(1-\gamma) d^{+}\right) F\left(t_{i-1}\right)\right]\right\} \Delta t_{i}}
\end{aligned}
$$

Proof. In a fuzzy random environment, according to formulas (5), (15), and (18) and the nature of expectations, the following can be gotten:

$$
\begin{aligned}
& \tilde{c}_{\gamma}^{+}=\frac{E^{\mathrm{Q}}\left[(1-\delta) \sum_{i=1}^{n} \exp \left(-\int_{0}^{t_{i}} r_{s} d s\right)\left[F\left(t_{i}\right)-F\left(t_{i-1}\right)\right]\right]_{\gamma}^{+}}{E^{\mathrm{Q}}\left[\sum_{i=1}^{n} \exp \left(-\int_{0}^{t_{i}} r_{s} d s\right) \times 1_{\left\{\tau>t_{i}\right\}} \Delta t_{i}+(1 / 2) \sum_{i=1}^{n} \exp \left(-\int_{0}^{t_{i}} r_{s} d s\right) \times\left[F\left(t_{i}\right)-F\left(t_{i-1}\right)\right] \Delta t_{i}\right]_{\gamma}^{-}} \\
& E^{\mathrm{Q}}\left[(1-\delta) \sum_{i=1}^{n} \exp \left(-\int_{0}^{t_{i}} r_{s} d s\right)\left[F\left(t_{i}\right)-F\left(t_{i-1}\right)\right]\right]_{\gamma}^{+}
\end{aligned}
$$




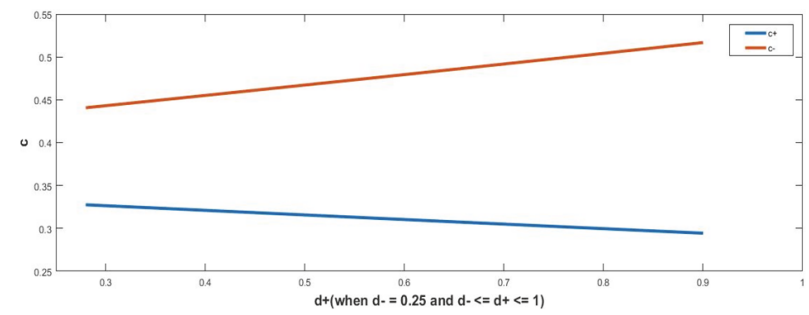

FIGURE 1: the fuzzy credit spreads vary with $\mathrm{d}^{+}$.

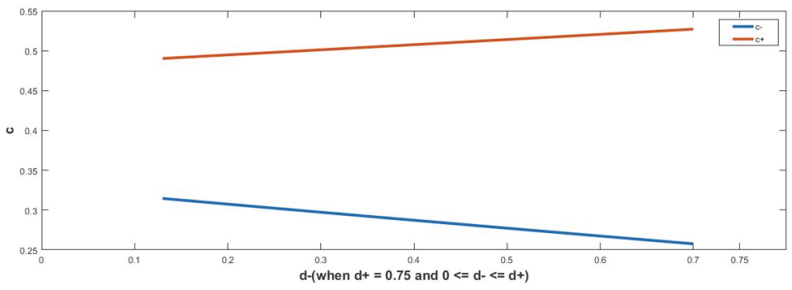

FIGURE 2: The fuzzy credit spreads vary with $\mathrm{d}^{-}$.

$$
\begin{gathered}
==(1-\delta) \sum_{i=1}^{n} e^{-\left(1-(1-\gamma) c^{-}\right) r C(t, T)-A(t, T)}\left[\left(1+(1-\gamma) d^{+}\right) F\left(t_{i}\right)-\left(1-(1-\gamma) d^{-}\right) F\left(t_{i-1}\right)\right], \\
E^{Q}\left[\sum_{i=1}^{n} \exp \left(-\int_{0}^{t_{i}} r_{s} d s\right) \times 1_{\left\{\tau>t_{i}\right\}} \Delta t_{i}\right]_{\gamma}^{-}=\sum_{i=1}^{n} e^{-\left(1+(1-\gamma) c^{+}\right) r C(t, T)-A(t, T)}\left[1-\left(1+(1-\gamma) d^{+}\right) F\left(t_{i}\right)\right], \\
E^{Q}\left[\frac{1}{2} \sum_{i=1}^{n} \exp \left(-\int_{0}^{t_{i}} r_{s} d s\right) \times\left[F\left(t_{i}\right)-F\left(t_{i-1}\right)\right] \Delta t_{i}\right]_{\gamma}^{-} \\
=\frac{1}{2} \sum_{i=1}^{n} e^{-\left(1+(1-\gamma) c^{+}\right) r C(t, T)-A(t, T)}\left[\left(1-(1-\gamma) d^{-}\right) F\left(t_{i}\right)-\left(1+(1-\gamma) d^{+}\right) F\left(t_{i-1}\right)\right] \Delta t_{i} .
\end{gathered}
$$

Bring the expected results into formula (5), and according to the monotonicity of function, this theorem can be proved. Finally, the level set $\gamma$-of total return swaps fair premium in the form of triangular fuzziness can be obtained: $\widetilde{s}_{\gamma}=$ $\left[\widetilde{s}_{\gamma}, \widetilde{s}_{\gamma}^{+}\right]$.

Note. In view of the literature [14], we give a reasonable hypothesis: the divergence factor $a_{5}, b_{5}$ can be assumed to be $a_{5}=d^{-} F(t), b_{5}=d^{+} F(t)$, where $0<d^{-}, d^{+}<1$ (so $d^{-}, d^{+}$will correspond with the $a_{5}, b_{5}$, which will be able to characterize the degree of fuzziness of information). The assumption is feasible because the divergence factor $a_{5}, b_{5}$ is associated with the fuzziness of the volatility of financial markets.

To illustrate the validity of the model, we have made several calculations using the above formula in simulations; the results of simulations of the left and right ends of the fuzzy form of the credit default swap fair premium $\gamma$-cut set are given. Specifically, the influence of the fuzzy degree of the market information and the investor's subjective judgment reliability on the premium section of the credit default swaps is investigated, and the results are shown in Figures 1-2. As a numerical illustration, we show the following.

Figures 1-2 show that the interval length of the credit default swaps fair premium $\gamma$-cut set gradually broadens with increases in the degree of fuzziness of information; that is, the lower and upper bounds are gradually widen. These results show that the degree of fuzziness in market information has a significant impact on credit default swap price changes with the swap price range proportional to the degree of fuzziness of information.

\section{Conclusion}

On the basis of real world observations that limited disclosure of market information may cause asymmetry in information flows, this paper introduced fuzzy analysis into the credit default swap pricing model and then constructed a credit 
default swap pricing model that incorporates triangular fuzzy intervals. Compared to $[7,15,16]$, the model in this paper can solve some inherent problems such as the asymmetry of market information flows and the low evaluations caused by inadequate disclosure of information. Of course, we are not able to examine the model in the real market as we are unable to get either the necessary market data or stability control in the form of interval numbers. All the above issues will be included as part of our future studies.

\section{Data Availability}

By setting some parameters to the model, the data of this paper can be obtained by means of simulation through the use of MATLAB R2010a, and I state that the data in my manuscript is available.

\section{Conflicts of Interest}

The authors declare that there are no conflicts of interest regarding the publication of this paper or the received funding mentioned in the "Acknowledgments".

\section{Authors' Contributions}

Liang Wu is the main writer of the framework and content of this article, Jian-guo Sun carried out numerical simulation, and Xian-bin Mei reviewed the full text.

\section{Acknowledgments}

The work was supported by the project funded by China Postdoctoral Science Foundation (no. 2017M622325).

\section{References}

[1] L. Wu and Y. Zhuang, "A reduced-form intensity-based model under fuzzy environments," Communications in Nonlinear Science and Numerical Simulation, vol. 22, no. 1-3, pp. 1169-1177, 2015.

[2] L. Wu, Y. M. Zhuang, and W. Li, "A new default intensity model with fuzziness and hesitation," International Journal of Computational Intelligence Systems, vol. 9, no. 2, pp. 340-350, 2016.

[3] L. Wu, J.-F. Liu, J.-T. Wang, and Y.-M. Zhuang, "Pricing for a basket of LCDS under fuzzy environments," SpringerPlus, vol. 5, no. 1, article no. 1747, 2016.

[4] L. Wu, J.-t. Wang, J.-f. Liu, and Y.-m. Zhuang, "The total return swap pricing model under fuzzy random environments," Discrete Dynamics in Nature and Society, Art. ID 9762841, 10 pages, 2017.

[5] L. Wu, Y. Zhuang, and X. Lin, "Credit derivatives pricing model for fuzzy financial market," Mathematical Problems in Engineering, Article ID 879185, Art. ID 879185, 6 pages, 2015.

[6] E. Agliardi and R. Agliardi, "Fuzzy defaultable bonds," Fuzzy Sets and Systems, vol. 160, no. 18, pp. 2597-2607, 2009.

[7] I. H. Gökgöz, Ö. Uğur, and Y. Y. Okur, "On the single name CDS price under structural modeling," Journal of Computational and Applied Mathematics, vol. 259, no. part B, pp. 406-412, 2014.
[8] W. Schoutens and J. Cariboni, Lévy Processes in Credit Risk, John Wiley \& Sons, Inc., Hoboken, NJ, USA, 2012.

[9] R. C. Merton, "On the pricing of corporate debt: the risk structure of interest rates," The Journal of Finance, vol. 29, no. 2, pp. 449-470, 1974.

[10] S. G. Kou and H. Wang, "First passage times of a jump diffusion process," Advances in Applied Probability, vol. 35, no. 2, pp. 504531, 2003.

[11] L. A. Zadeh, "Fuzzy sets," Information and Control, vol. 8, no. 3, pp. 338-353, 1965.

[12] A. Kaufmann and M. M. Gupta, Introduction to fuzzy arithmetic: Theory and applications, Van Nostrand Reinhold Co, 1985.

[13] R. L. Hao, Pricing Credit Securities in the Contagious Model [Ph.D. thesis], Dissertation Shanghai Jiao Tong University, 2011.

[14] Y. Yoshida, "The valuation of European options in uncertain environment," European Journal of Operational Research, vol. 145, no. 1, pp. 221-229, 2003.

[15] W. Gu, Y. Liu, and R. Hao, "Attenuated Model of Pricing Credit Default Swap under the Fractional Brownian Motion Environment," Journal of Mathematical Finance, vol. 06, no. 02, pp. 247-259, 2016.

[16] W. Chen and X. He, "Pricing credit default swaps under a multi-scale stochastic volatility model," Physica A: Statistical Mechanics and its Applications, vol. 468, pp. 425-433, 2017. 


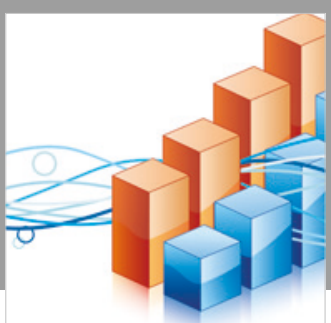

Advances in

Operations Research

\section{-n-m}
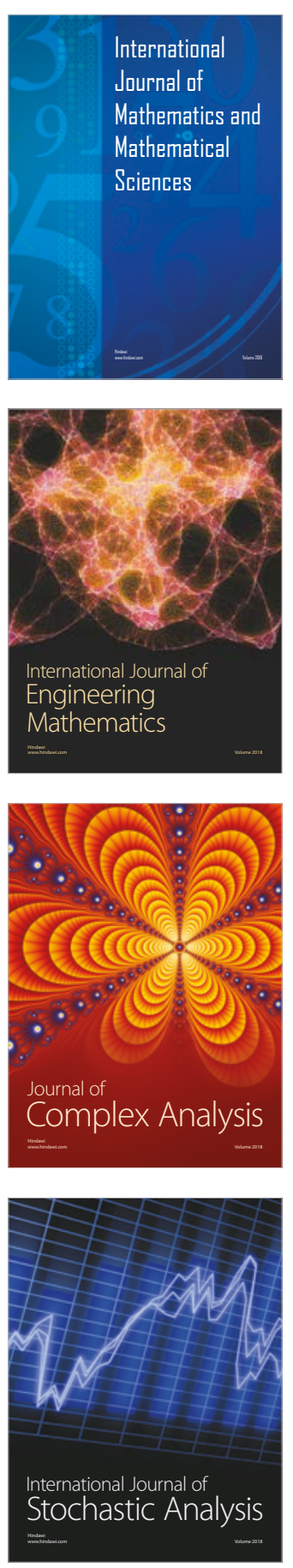
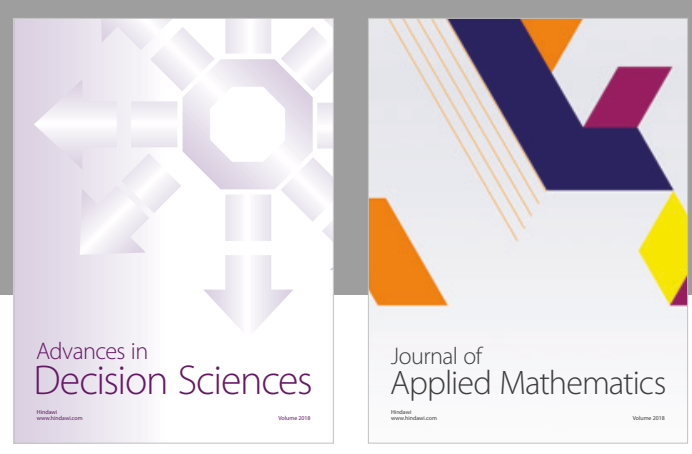

Journal of

Applied Mathematics
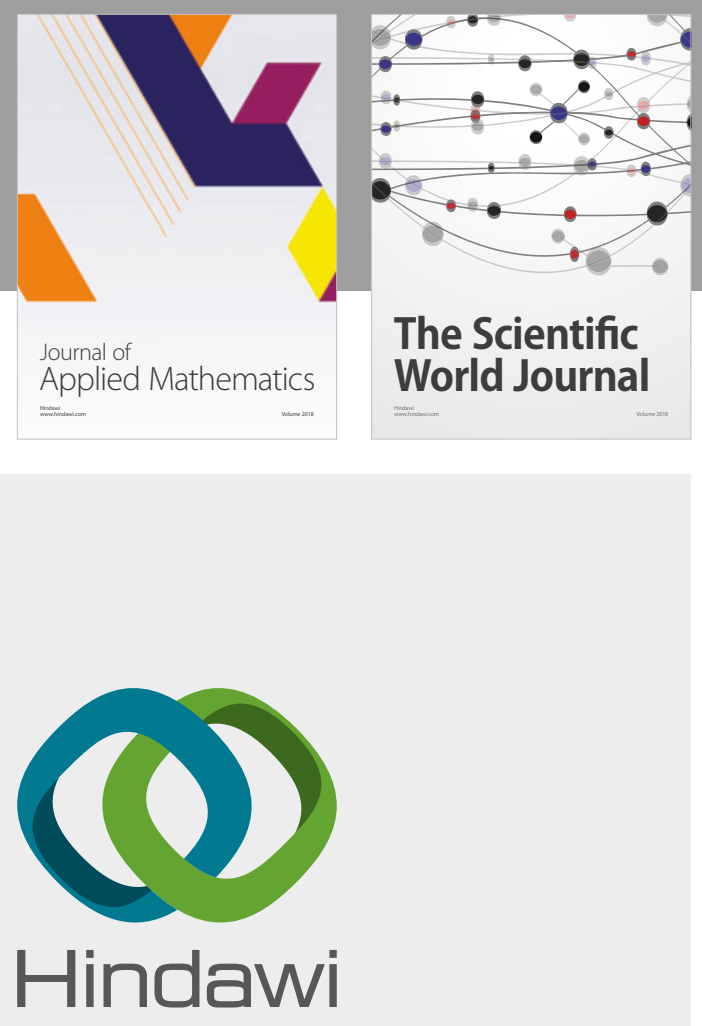

Submit your manuscripts at

www.hindawi.com

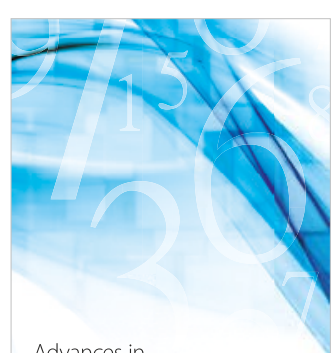

Advances in
Numerical Analysis
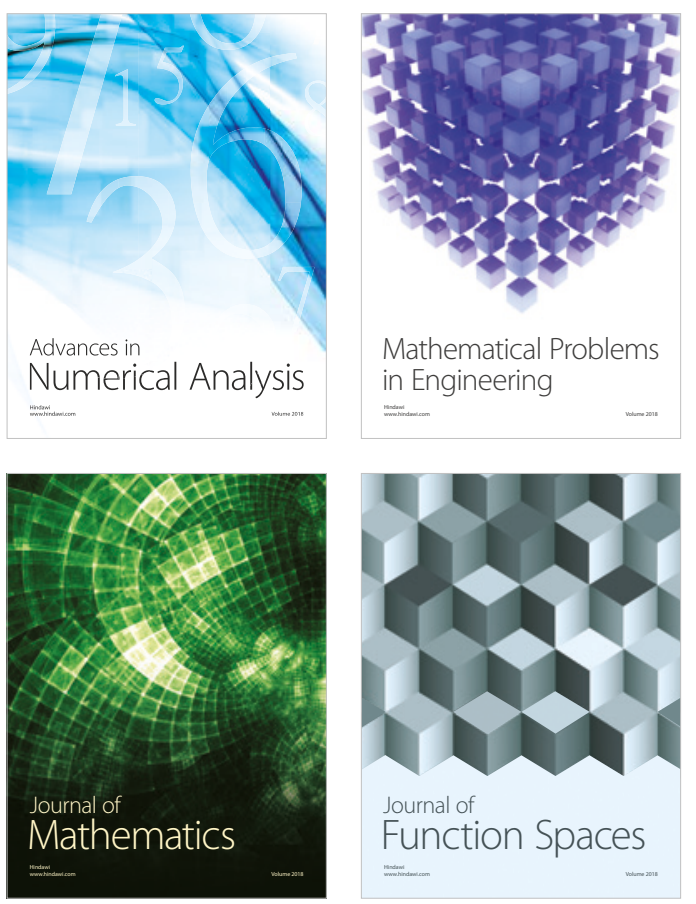

Mathematical Problems in Engineering

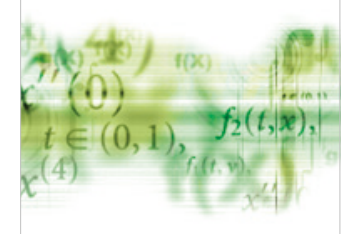

International Journal of

Differential Equations

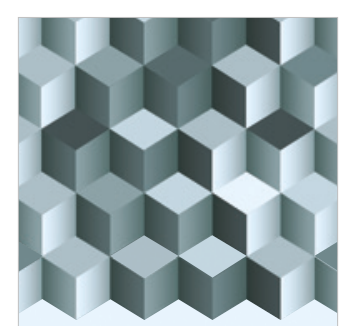

Journal of

Function Spaces

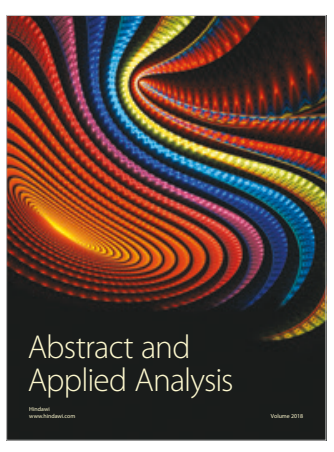

The Scientific

World Journal

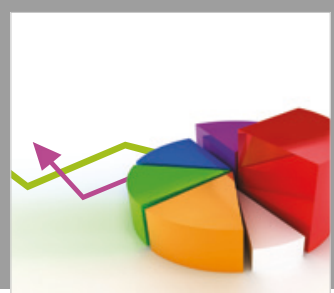

Journal of

Probability and Statistics
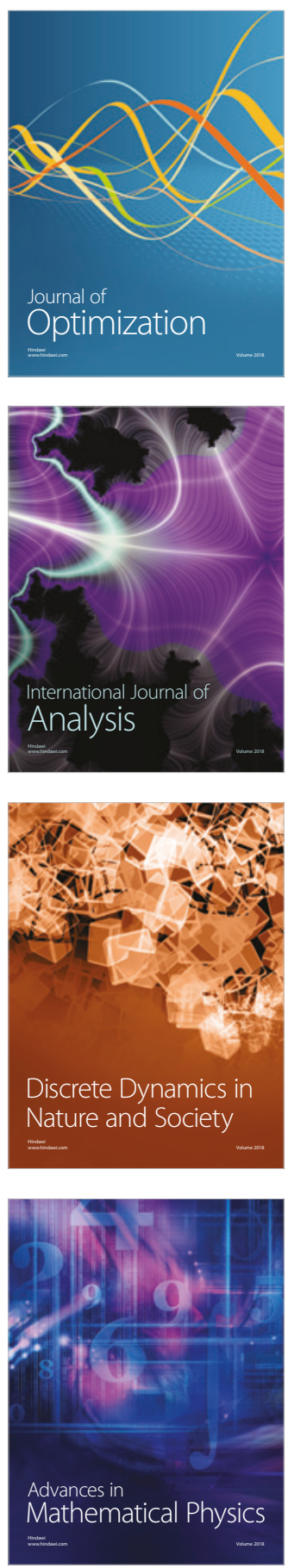